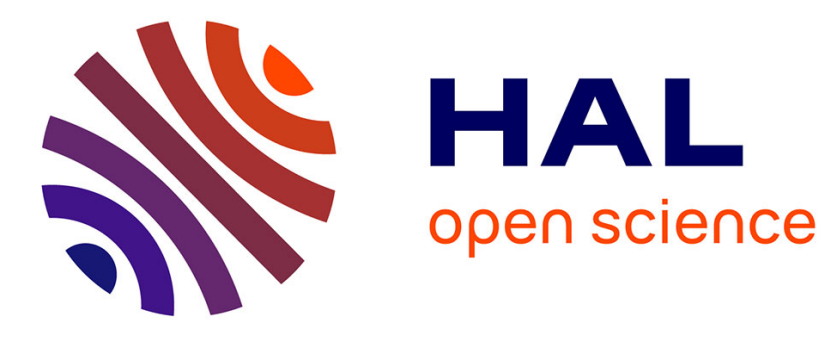

\title{
Prebreakdown in low voltage varistors and its relation with deep levels
}

\author{
P. Gaucher, R.L. Perrier, J.P. Ganne
}

\section{To cite this version:}

P. Gaucher, R.L. Perrier, J.P. Ganne. Prebreakdown in low voltage varistors and its relation with deep levels. Revue de Physique Appliquée, 1990, 25 (8), pp.823-830. 10.1051/rphysap:01990002508082300 . jpa-00246244

\section{HAL Id: jpa-00246244 https://hal.science/jpa-00246244}

Submitted on 1 Jan 1990

HAL is a multi-disciplinary open access archive for the deposit and dissemination of scientific research documents, whether they are published or not. The documents may come from teaching and research institutions in France or abroad, or from public or private research centers.
L'archive ouverte pluridisciplinaire HAL, est destinée au dépôt et à la diffusion de documents scientifiques de niveau recherche, publiés ou non, émanant des établissements d'enseignement et de recherche français ou étrangers, des laboratoires publics ou privés. 


\title{
Prebreakdown in low voltage varistors and its relation with deep levels
}

\author{
P. Gaucher, R. L. Perrier and J. P. Ganne \\ Thomson CSF/LCR, Domaine de Corbeville, 91401 Orsay, France \\ (Reçu le 17 novembre 1989, révisé le 8 février 1990, accepté le 30 avril 1990)
}

\begin{abstract}
Résumé. - Des extréma locaux du coefficient de non-linéarité ont été observés au-dessous de la tension de seuil de plusieurs varistances basse tension, dans la région du courant de fuite. La valeur du champ électrique où ces maxima apparaissent n'est pas thermiquement activée. Elle est liée à la présence de pièges profonds dans la bande interdite de l'oxyde de zinc. Ces pièges ont été étudiés par spectroscopie d'admittance (tangente de pertes en fonction de la température). L'énergie de ces pièges et leur relative proportion par rapport aux niveaux donneurs a été déduite d'un modèle de barrière électrique au joint de grain. L'augmentation de la non-linéarité au-dessous du seuil principal s'explique par une diminution brutale de la hauteur de barrière lorsque le niveau de Fermi traverse le niveau d'un piège à l'intérieur d'un grain.
\end{abstract}

\begin{abstract}
The non-linearity coefficient $\alpha$ of several low voltage varistors shows some local maxima in the prebreakdown region (where the leakage current is generally defined). The field at which these maxima appear is not thermally activated and is related to the presence of deep levels in the forbidden gap of the zinc oxide. These levels are studied by an admittance spectroscopy method based on loss tangent measurements as a function of temperature. A barrier model enabled us to derive the energy of the levels and the relative proportion of deep levels to donor levels. The increase of non linearity below the main threshold can be explained by an abrupt jump of the barrier height when the Fermi level crosses the deep level of the trap inside the grain.
\end{abstract}

\section{Introduction.}

Low voltage varistors are zinc oxide based ceramic devices performing protection against electrical pulses due to lightning, induced currents or electrostatic discharges. They are an alternative route for secondary protection, instead of Zener diodes, combining low cost and high energy capabilities.

The current-voltage characteristic can be divided into four regions that we have labelled as $\mathrm{O}, \mathrm{PB}, \mathrm{B}$ and $U$ on the experimental curve figure 1 :

- an ohmic region $(\mathrm{O})$ for current densities lying around $10^{-8} \mathrm{~A} / \mathrm{cm}^{2}$,

- a prebreakdown region (PB) between $10^{-6}$ and $10^{-3} \mathrm{~A} / \mathrm{cm}^{2}$ where non linear effects start to appear. This region corresponds usually to the voltage of the varistor at rest between two current pulses,

- a breakdown region (B) near $1 \mathrm{~mA} / \mathrm{cm}^{2}$ where the non linearity is maximum and consequently as well the clamping properties during a transient pulse of voltage,

- an upturn region (U) where non linearity and clamping properties both decrease owing to series resistance effect due to the grain bulk.
The $\mathrm{O}$ region is related to the thermally activated current flowing through the grain boundary. According to the diagram of figure 2 , this current is given by the difference between a forward current through a barrier whose height is $\phi_{\mathrm{B} 0}+q V_{1}$ and a reverse current through a barrier whose height is $\phi_{\mathrm{B} 0}-q V_{2}[1]$ :

$$
\begin{aligned}
I=A^{*} T^{2} \exp \left[-\left(\phi_{\mathrm{B} 0}-q V_{1}\right) / k T\right]- \\
-A^{*} T^{2} \exp \left[-\left(\phi_{\mathrm{B} 0}+q V_{2}\right) / k T\right]
\end{aligned}
$$

where $A^{*}$ is the Richardson constant, $q$ the electron charge, $\phi_{\mathrm{B} 0}$ the barrier height at zero voltage and $V_{1}$ and $V_{2}$ the variation of potential on respectively the forward and reverse side of the junction when an external voltage $V=V_{1}+V_{2}$ is applied (see Fig. 2).

When $q V$ and $q V_{1} \ll k T$, a first order development gives the ohmic relation between $I$ and $V$ :

$$
I=\left(A^{*} T / k\right) \cdot \exp \left(-\phi_{\mathrm{B}} / k T\right) \cdot q V
$$

and the non linearity coefficient $\alpha$, defined as :

$$
\alpha=\mathrm{d}(\operatorname{Ln} I) / \mathrm{d}(\operatorname{Ln} V)
$$

is equal to one. 


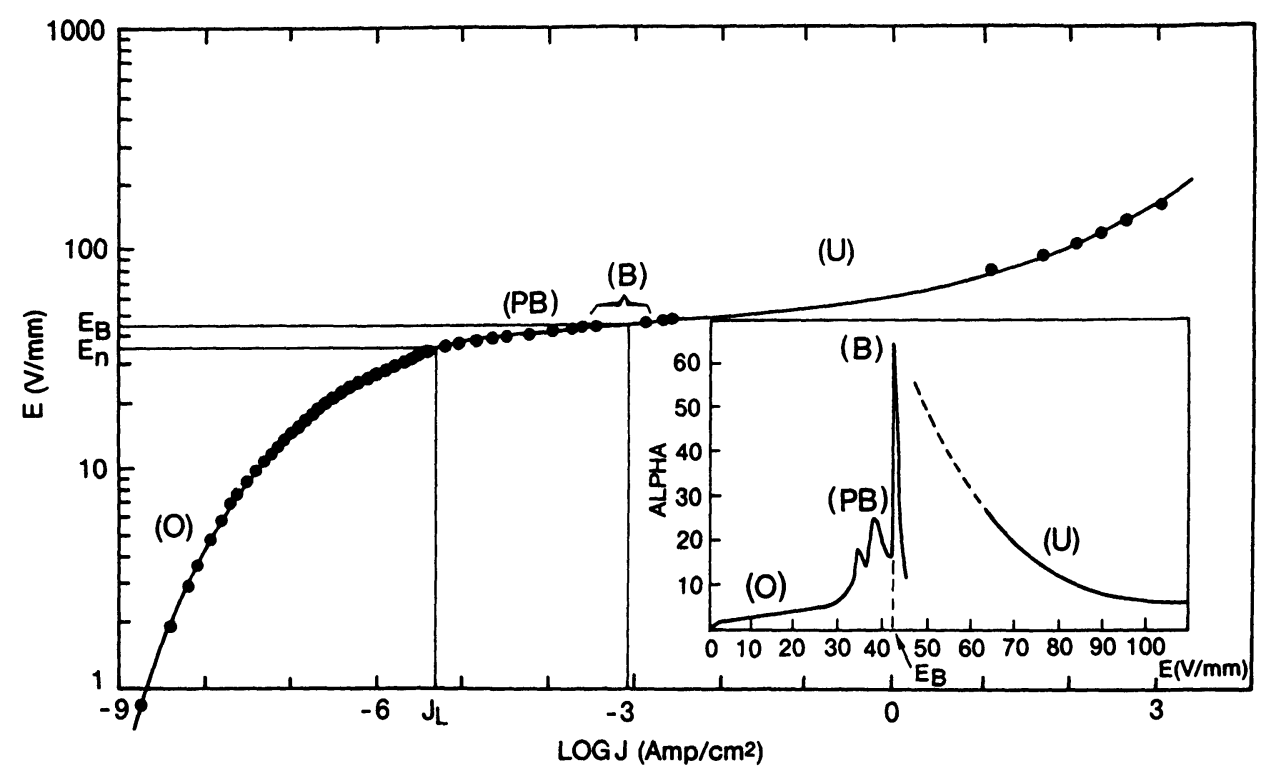

Fig. 1. - Electrical field versus current density for a commercial disc varistor (Matsushita 10DK470).
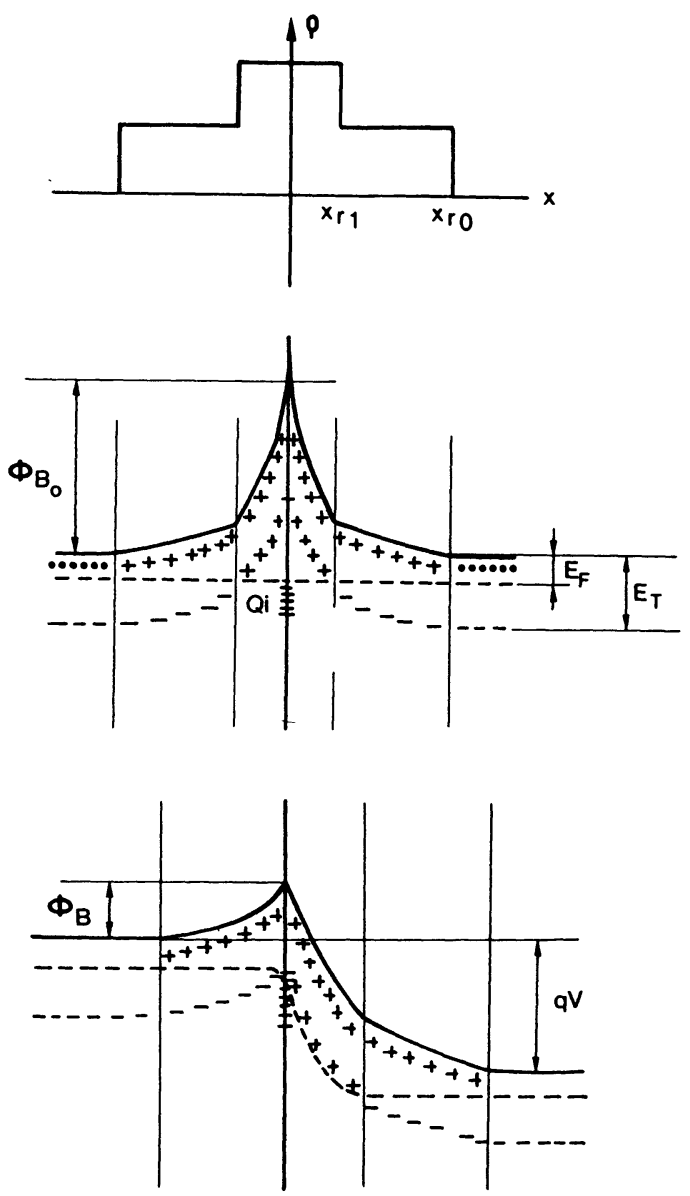

Fig. 2. - Grain boundary barrier model. Top : charge distribution, center: barrier with no applied voltage, bottom : barrier with a bias voltage corresponding to the prebreakdown region.
In the PB region, the increase of $\alpha$ is due to a decrease of the barrier height $\phi_{\mathrm{B}}(V)=\phi_{\mathrm{B} 0}-q V_{1}$ which is usually supposed to follow a parabolic law [1] (in the absence of deep levels) :

$$
\phi_{\mathrm{B}}(V)=\phi_{\mathrm{B} 0}\left(1-q V / 4 \phi_{\mathrm{B} 0}\right)^{2} .
$$

The region $\mathrm{B}$ corresponds to a very sharp increase of $\alpha$ for an applied voltage $V_{\mathrm{B}}$ depending on the number of grain boundaries perpendicular to the field. The voltage drop is approximately in the range 2-3 $\mathrm{V}$ per grain boundary and the maximum value of $\alpha$ is $V_{B} / 2 k T$ [2]. At this voltage, a tunnelling mechanism is assumed to trigger the avalanche effect resulting from the formation of electron-hole pairs by impact ionisation [3]. This breakdown voltage $V_{\mathrm{B}}$ is generally obtained at a current density of about $1 \mathrm{~mA} / \mathrm{cm}^{2}$. The energy per unit volume dissipated at this moment in the grain boundary region (of thickness about 0.1 micron) during the measurement is nearly $300 \mathrm{~J} / \mathrm{cm}^{3}$. This value is usually considered as the maximum value admissible by the device under test [2]. To protect the device from degradation effects, the higher voltage measurements are generally made under pulses of short duration. Despite these precautions, at very high currents (up to $10^{3} \mathrm{~A} / \mathrm{cm}^{2}$ ), the non linearity still decreases in the $\mathrm{U}$ region. The classical interpretation of this is the following : the barrier height $\phi_{\mathrm{B}}$ being cancelled for $V>4 \phi_{\mathrm{B} 0}$, the only remaining resistance is that of grain bulk $R_{\mathrm{S}}$ and the voltage drop along $n$ grain boundaries is :

$$
V=4 n \phi_{\mathrm{B} 0}+R_{\mathrm{S}} \cdot I .
$$


The goal of this paper is to achieve a better description of the $\mathrm{PB}$ region where the device spends most of the time (the nominal voltage is generally $20 \%$ lower than the breakdown voltage). In this region, thermal effects are negligible and all the properties are related to electronic processes in the forbidden gap. These processes are supposed to be very dependent on the electronic levels investigated by admittance spectroscopy.

\section{Experiments.}

Four low voltage varistors with different breakdown fields $E_{\mathrm{B}}$ and leakage current densities $J_{\mathrm{L}}$ (measured at the nominal voltage) have been studied : samples A, B and C are commercial ones (respectively Matsushita 10DK270, General Electric GEMOV $27 Z 1$ and Matsushita 10DK470) ; sample D has been prepared in our laboratory by a classical mixed oxides method with additives to improve grain growth (titanium in place of the chromium and antimony used in medium and high voltage varistors). Values of the breakdown field $E_{\mathrm{B}}$ and of the leakage current density $J_{\mathrm{L}}$ are given in table $I$. The thickness of all discs being close to $1 \mathrm{~mm}$, the breakdown voltage $V_{\mathrm{B}}$ (in volts) is not very different from the breakdown field $E_{\mathrm{B}}$ (in volts $/ \mathrm{mm}$ ).

The current-voltage characteristics have been measured with a megohmmeter-picoammeter Sefelec DM 500 controlled by a microcomputer. The applied voltage is increased with constant steps of $1 \mathrm{~V}$. It is measured with a Hewlett-Packard multimeter. The settling time before each acquisition is $15 \mathrm{~s}$. We checked that the results are almost identical with settling times between 5 and $60 \mathrm{~s}$; we finally chose $15 \mathrm{~s}$. The non linear coefficient $\alpha$ was estimated by interpolation between two adjacent points of the curve (see Appendix). The resolution of the method is related to the voltage increment used.

For temperature variations, the sample was placed in a cryostat SMC-TBT (France) with an electronic regulation from -200 to $+200{ }^{\circ} \mathrm{C}$.

The current voltage measurements give only informations on the free carriers flowing through the

Table I. - Main characteristics of the studied varistors.

\begin{tabular}{|c|c|c|c|}
\hline Sample & Origin & $E_{\mathrm{B}}(\mathrm{V} / \mathrm{mm})$ & $J_{\mathrm{f}}\left(\mu \mathrm{A} / \mathrm{cm}^{2}\right)$ \\
\hline A & ZNR 10K 270 & 22 & 70 \\
\hline B & GEMOV 27Z1 & 27 & 35 \\
\hline C & ZNR 10K 470 & 42 & 13 \\
\hline D & Laboratory & 50 & 8 \\
\hline
\end{tabular}

material under DC field. Additional information on trapped carriers can be obtained by admittance spectroscopy: this technique consists in measuring the AC response of the material at low level, at different temperatures and frequencies.

Admittance spectroscopy was performed on measuring the capacitance and loss tangent at 12 frequencies between $120 \mathrm{~Hz}$ and $10 \mathrm{MHz}$ (impedance bridge HP $4262 \mathrm{~A}$ and $4275 \mathrm{~A}$ ) during a linear temperature $\mathrm{ramp}\left(200^{\circ} \mathrm{C} / \mathrm{h}\right)$ varying from -200 to $+150{ }^{\circ} \mathrm{C}$.

\section{Variations of the non linear coefficient $\alpha$ with voltage.}

According to the classical models of barrier breakdown [1, 4], the non linear coefficient $\alpha$ should increase monotonically up to the main breakdown, because of the steadily decrease of barrier height $\phi_{\mathrm{B}}$. The thermal saturation of the junction at the main breakdown leads then to a subsequent decrease of $\alpha$ as is shown in the icon of figure 1. For this reason, the peak of $\alpha$ is very sharp in DC measurements. We found that this is not the case for low voltage varistors. Figure 3 shows the variation of $\alpha$ versus electrical field for the studied varistors. In addition to the sharp peak due to the main breakdown occurring at the field $E_{\mathrm{B}}$, a few secondary maxima can be seen for all samples. The reproducibility of these behaviours has been checked, either when varying settling times, or with increasing or decreasing voltages.

These maxima cannot be due to an error in the method of extracting the $\alpha$ values. At 20 volts, the absolute error on $\alpha$ is less than 4 (see Eq. (28) in Appendix), and the magnitude of the peaks of sample A and B is 11 and 16 respectively. Samples C and $\mathrm{D}$ have $\alpha$ secondary peak values up to 25 with a maximum error of \pm 8 .

The described effect can be very hardly seen in the $J-E$ curve because of the logarithmic scales, but it is always present on the $\alpha-E$ curve.

We could not observe it on classical medium or high voltage varistors.

In order to investigate the influence of the temperature on the position of these maxima, we have made the same measurements between -50 and $+150{ }^{\circ} \mathrm{C}$ for sample B (Fig. 4). Contrary to the breakdown field which is shifted towards lower values when the temperature increases, the positions of the maxima in the $\mathrm{PB}$ region do not move with temperature, but their magnitude strongly decrease with increasing temperature (as for the $\mathrm{B}$ region).

If we plot $\alpha$ as a function of the current density $J$, a very different behaviour is observed. The $B$ region is always at the same value of $J=J_{\mathrm{B}}$ (very close to $1 \mathrm{~mA} / \mathrm{cm}^{2}$ ), but the PB secondary maxima shift towards $J_{\mathrm{B}}$ when the temperature increases (Fig. 5). 


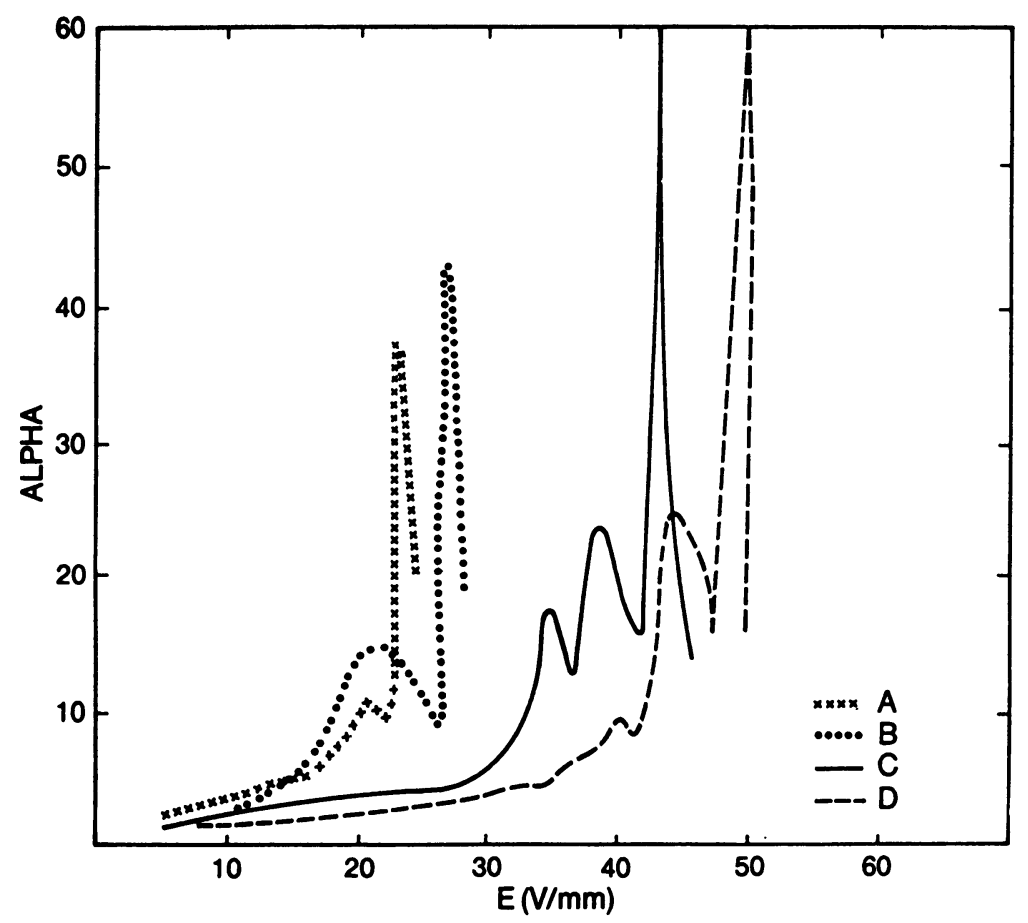

Fig. 3. - Variation of the non linear coefficient up to the breakdown field $E_{\mathrm{B}}$ for the four samples A, B, C and D. Prebreakdown are shown as secondary maxima below $E_{\mathrm{B}}$.

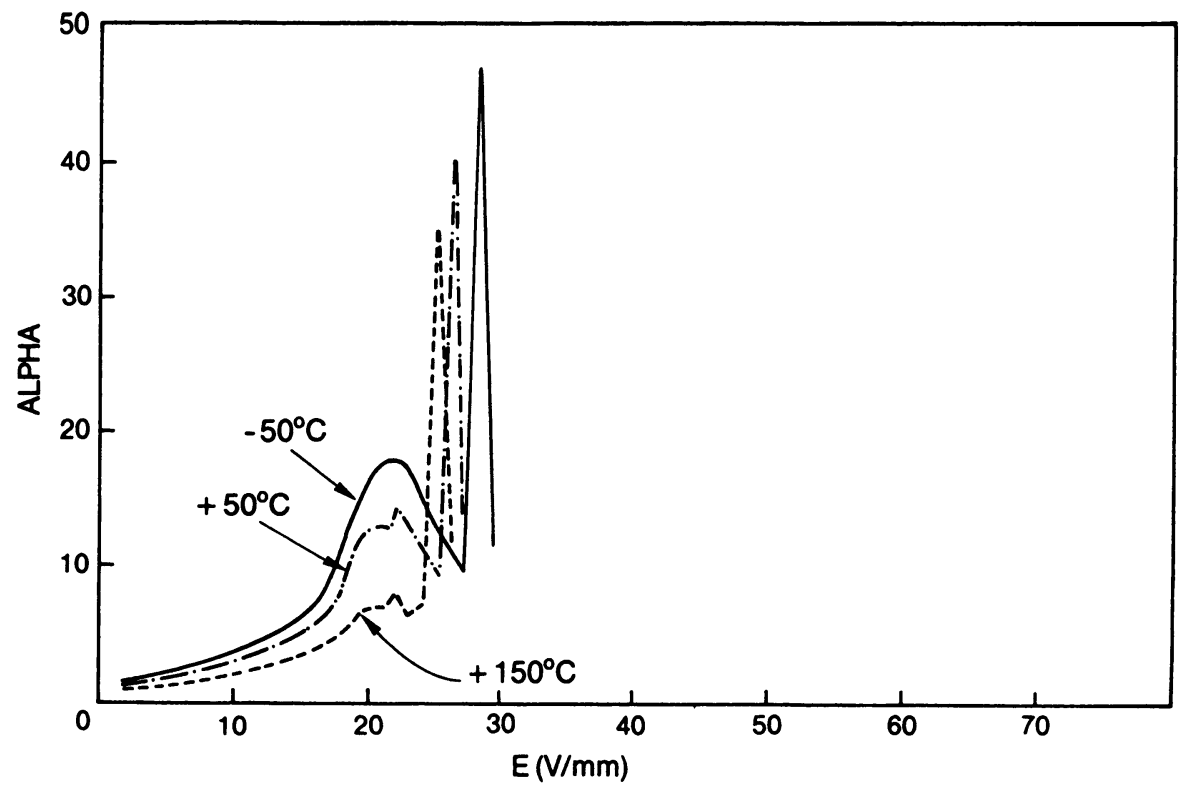

Fig. 4. - Non linear coefficient as a function of electrical field at different temperatures for sample B.

In some cases, they gradually merge with the main breakdown peak.

As the main threshold is related to the band gap energy of $\mathrm{ZnO}(3.2 \mathrm{eV})$, it seems questionable if these sub-band gap effects are related to deep levels in the semi-conducting grains.

\section{Deep levels relaxations.}

In the presence of a donor level (density $N_{0}$ ) and a deep trap level (density $N_{1}$ ), the dielectric function (without any bias voltage) [1] can be generalized. The donor level causes a Maxwell-Wagner type relaxation (with a time constant distribution $f(\tau)$ ) and each deep trap causes a Debye type relaxation (with time constant $\tau_{i}$ ) [6].

$$
\begin{aligned}
\varepsilon^{\prime} & =\int_{0}^{\infty} \frac{\varepsilon_{\mathrm{c}} f(\tau) \mathrm{d} \tau}{1+\omega^{2} \tau^{2}}+\sum_{i} \frac{\varepsilon_{i}}{1+\omega^{2} \tau_{i}^{2}} \\
\varepsilon^{\prime \prime} & =\frac{\sigma_{0}}{\varepsilon_{0} \omega}+\int_{0}^{\infty} \frac{\varepsilon_{\mathrm{c}} \omega \tau f(\tau) \mathrm{d} \tau}{1+\omega^{2} \tau^{2}}+\sum \frac{\varepsilon_{i} \omega \tau_{i}}{1+\omega^{2} \tau_{i}^{2}}
\end{aligned}
$$




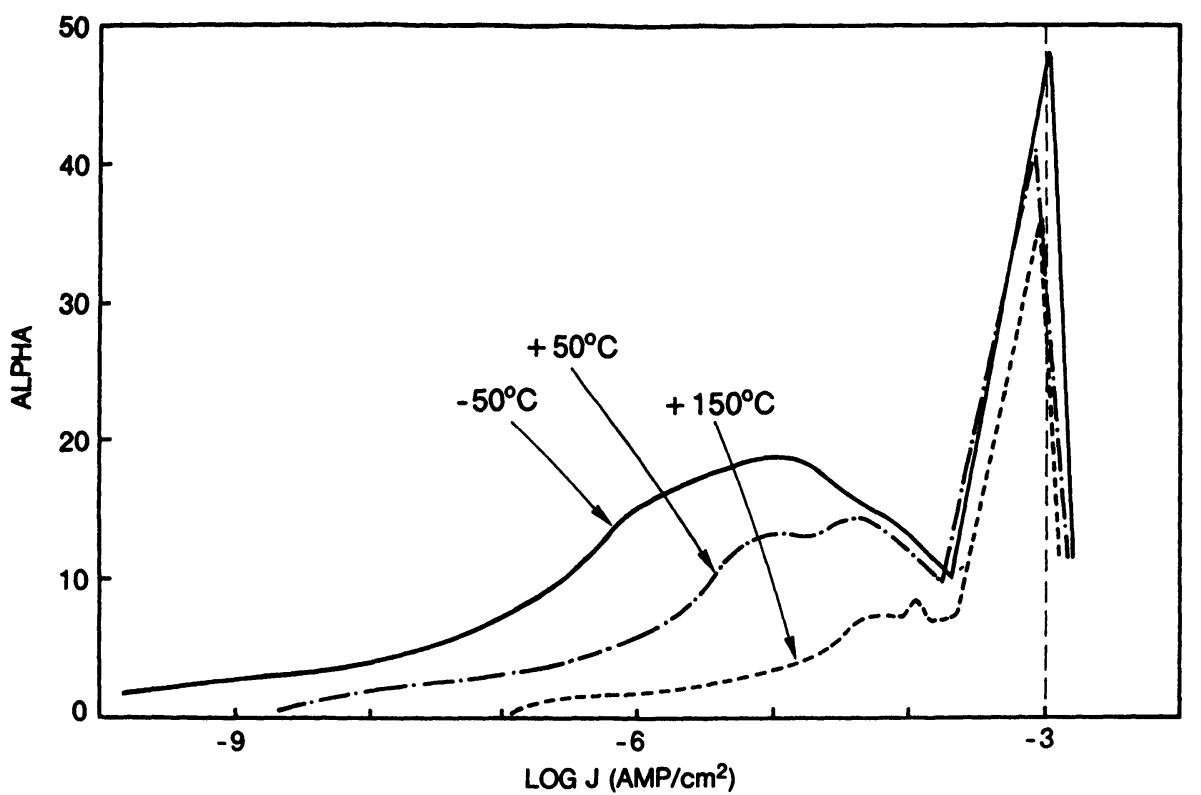

Fig. 5. - Non linear coefficient as a function of current density at different temperatures for sample B.

where $\varepsilon^{\prime}$ and $\varepsilon^{\prime \prime}$ are the real and imaginary parts of the dielectric function, and $\varepsilon_{i}, \varepsilon_{\mathrm{c}}$ the contribution of the deep level $i$ and of the donor levels to it. The Maxwell-Wagner effect at room temperature is present at frequencies higher than $10 \mathrm{MHz}$ [1]. It could be observed at much lower frequency, but only when cooling at temperatures well below ambient.

In the frequency and temperature range we consider here, we assume that the integrals in equations (6) and (7) are respectively equal to $\varepsilon_{\mathrm{c}}$ and 0 . So, only the relaxations of the deep levels are of importance.

Considering one deep level with a density $N_{1}$, the Poisson's equation :

$$
\Delta \phi=\rho / \varepsilon_{0} \varepsilon^{\prime}
$$

can be solved, with the charge density $\rho(x)$ represented in figure 2 . The potentiel $\phi(x)$ along the direction $x$ perpendicular to the grain boundary obeys the boundary conditions :

$$
\begin{gathered}
\phi\left(0^{+}\right)=\phi\left(0^{-}\right) \\
\mathrm{d} \phi / \mathrm{d} x\left(0^{+}\right)=\mathrm{d} \phi / \mathrm{d} x\left(0^{-}\right)=Q_{\mathrm{i}} / \varepsilon_{0} \varepsilon \\
q \phi\left(-x_{\ell 1}\right)=E_{1} \text { and } q \phi\left(x_{\mathrm{r} 1}\right)=E_{1}-q V
\end{gathered}
$$

$Q_{\mathrm{i}}$ is the interface charge at the grain boundary; on the direct (left) and reverse (right) side of the junction ; $x_{\ell 1}$ and $x_{\mathrm{r} 1}$ the depletion width due to deep levels (see Fig. 2 for notations). Using $x_{p 0}$ and $x_{\mathrm{r} 0}$, the depletion widths due to donors, as intermediate variables for calculation, one can derive the surface capacitance of the junction at low frequency and low amplitude of the alternating signal $\left(\omega \tau_{1} \ll 1\right)$ :

$$
C_{\mathrm{LF}}=\frac{2 q\left(N_{0}+N_{1}\right) \varepsilon_{0} \varepsilon^{\prime}}{Q_{\mathrm{i}}}
$$

and at high frequency (but still when the MaxwellWagner relaxation is not predominant, that is $\left.\omega \tau_{1} \gg 1\right)$ :

$$
C_{\mathrm{HF}}=\frac{2 q\left(N_{0}+N_{1}\right) \varepsilon_{0} \varepsilon^{\prime}}{Q_{\mathrm{i}}+2 N_{1} \sqrt{2 \varepsilon_{0} \varepsilon E_{1} / N_{0}}} .
$$

If $W$ is the width of the depletion region, we immediately get (according to Eq. (6)) :

$$
\begin{aligned}
& \varepsilon_{0} \varepsilon_{\mathrm{c}}=W \cdot C_{\mathrm{LF}} \\
& \varepsilon_{0} \varepsilon_{1}=W\left(C_{\mathrm{LF}}-C_{\mathrm{HF}}\right)=\varphi \cdot \varepsilon_{0} \varepsilon_{\mathrm{c}}
\end{aligned}
$$

with

$$
\varphi=\left(2 N_{1} / Q_{\mathrm{i}}\right) \sqrt{2 \varepsilon_{0} \varepsilon E_{1} / N_{0}} .
$$

Introducing the barrier height $\phi_{\mathrm{B}}$ [4] :

$$
\phi_{\mathrm{B}}=\frac{Q_{\mathrm{i}}^{2}}{8 \varepsilon_{0} \varepsilon N_{0}}
$$

where $Q_{\mathrm{i}}$ is the interface charge trapped at the grain boundary, we get :

$$
\varphi=\frac{N_{1}}{N_{0}} \sqrt{\frac{E_{1}}{\phi_{\mathrm{B}}}} .
$$

If we assume that the contribution $\varepsilon_{i}$ of the deep level in equations (6) and (7) is small compared to that of the donor level $\varepsilon_{\mathrm{c}}$, the real and imaginary part of the dielectric constant can be written (assuming only one deep level $i=1$ ) :

$$
\begin{aligned}
& \varepsilon^{\prime}=\varepsilon_{\mathrm{c}}=\varepsilon_{1} / \varphi \\
& \varepsilon^{\prime \prime}=\varepsilon_{1} g\left(\tau_{1}\right)
\end{aligned}
$$

where $g\left(\tau_{1}\right)$ is the Lorentz function :

$$
g\left(\tau_{1}\right)=\frac{\omega \tau_{1}}{1+\omega^{2} \tau_{1}^{2}} .
$$


The loss tangent $\operatorname{tg} \delta=\varepsilon^{\prime \prime} / \varepsilon^{\prime}=\varphi \cdot g\left(\tau_{1}\right)$ is maximum at the frequency $\omega_{1}=1 / \tau_{1}$, and its value is then equal to :

$$
\operatorname{tg} \delta_{\max }=\varphi / 2=1 / 2 \frac{N_{1}}{N_{0}} \sqrt{\frac{E_{1}}{\phi_{\mathrm{B}}}} .
$$

The maximum of the loss tangent is proportional to the density of the deep level $N_{1}$ multiplied by the square root of its energy.

\section{Admittance spectroscopy.}

For an electron trap of energy $E_{1}$ below the conduction band, the time constant $\tau_{1}$ is the inverse of the emission rate $e_{1}[5,6]$ :

$$
e_{1}=s_{1} v N_{\mathrm{C}} \exp \left(-\frac{E_{1}}{k T}\right)
$$

where $s_{1}$ is the capture cross section, $v$ the thermal velocity, $N_{\mathrm{C}}$ the effective density of states of the electrons in the conduction band. $\tau_{1}$ can be determined, at a given temperature, by the frequency $\omega_{1}$ corresponding to the maximum of loss tangent : $\tau_{1}=2 \pi / \omega_{1}$.

An equivalent method consists in varying temperature instead of frequency [7]. The relation between both variables is :

$$
\operatorname{Ln}\left(\omega_{1} / k T\right)=\operatorname{Ln}\left(s_{1} v N_{\mathrm{C}}\right)-E_{1} / k T .
$$

That means that the inverse of absolute temperature plays the same role as the logarithm of frequency. The classical shape of the Lorentz function can be retrieved with temperature measurements. This is shown in figure $6:$ the widths of the peaks are independent of the frequency and the activation energy $E_{1}$ can be estimated from the measured frequencies at the maximum.

The same method has been used to characterize the deep levels of the four samples A, B, C and D. The curves at $10 \mathrm{kHz}$ are plotted in figure 7. Three deep levels have been identified: $\mathrm{T} 1$ at $0.2 \mathrm{eV}$ on sample $\mathrm{B}, \mathrm{T} 2$ at $0.28 \mathrm{eV}$ on sample $\mathrm{C}$ (one can guess the presence of equivalent peaks on sample $A$ and $D$ by a shoulder on the main peak), T3 at $0.34 \mathrm{eV}$ on all samples.

The magnitude of the loss tangent peak gives the ratio of deep levels to donor levels, according to equation (19). A constant and classical value of barrier height $\phi_{\mathrm{B}}=0.8 \mathrm{eV}$ has been assumed. The results are reported in table II. The proportion of deep levels compared with the donor levels one can be either very high (70\% for level T1 in sample B) or very low (10\% for level T3 in sample C). Their influence on the Fermi level and therefore on the leakage current is certainly not negligible : by lowering the Fermi level, the deep traps decrease the grain conductivity and partially cancel the effect of the donor levels. A good equilibrium between donor and deep levels has to be found to provide low leakage currents and good clamping properties.

\section{Discussion.}

The comparison of the results of current-voltage measurements and admittance spectroscopy is instructive. Table II shows that a correlation seems to exist between the presence of a deep level of energy $E_{i}$ and that of a prebreakdown at a field $E_{\mathrm{PB}}$. The deep level T3 is correlated to a maximum of the non linearity coefficient $\alpha$ at a field corresponding to

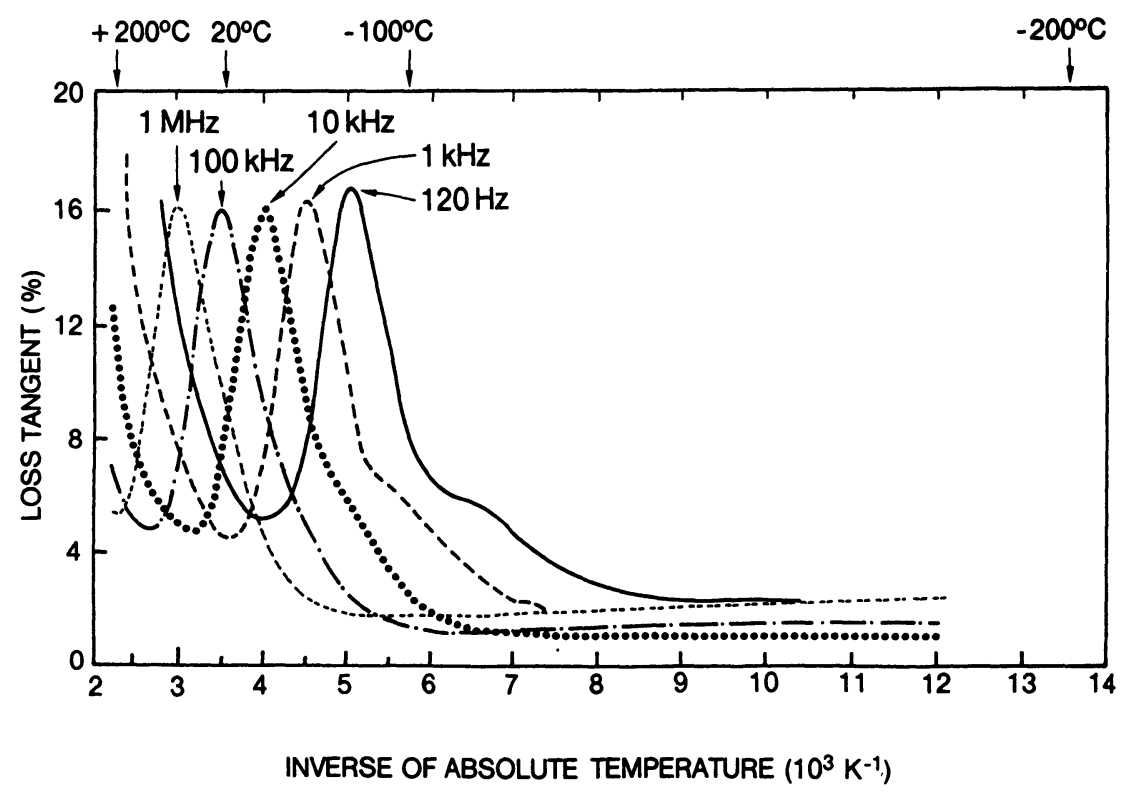

Fig. 6. - Admittance spectroscopy of sample D between $120 \mathrm{~Hz}$ and $1 \mathrm{MHz}$. 


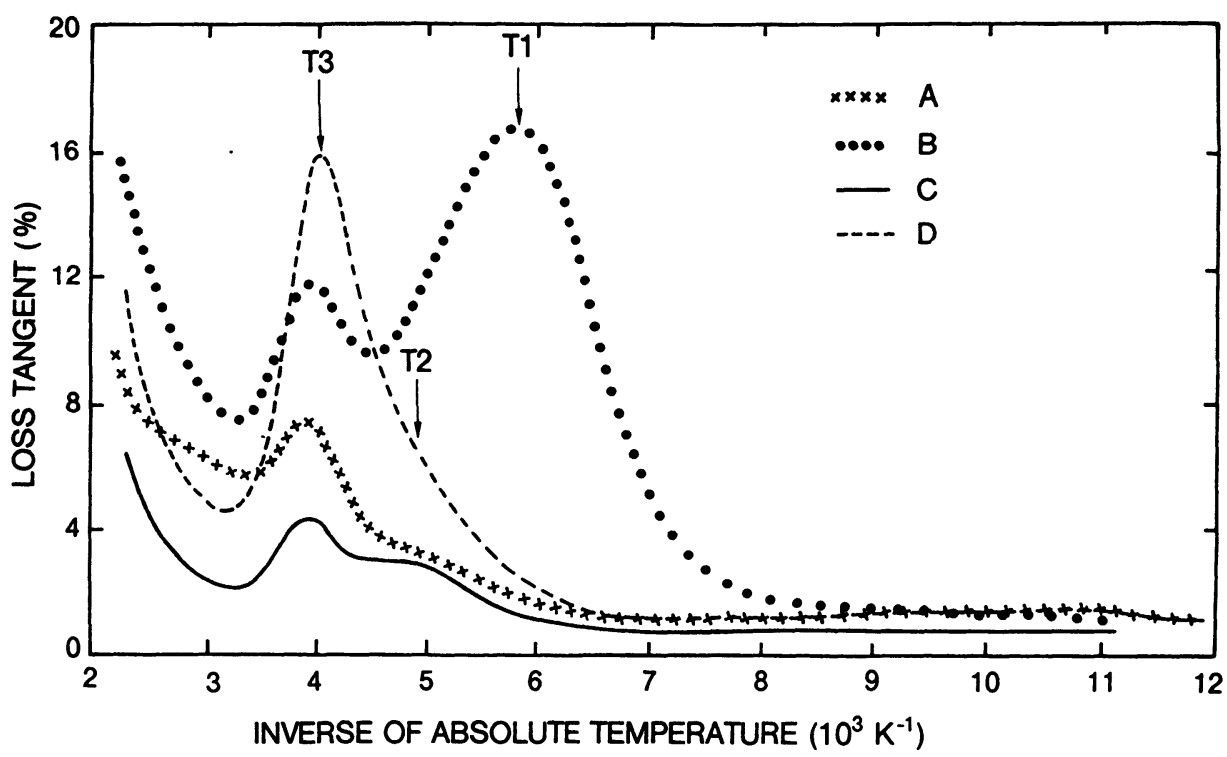

Fig. 7. - Admittance spectroscopy at $10 \mathrm{kHz}$ of the four varistors studied.

Table II. - Summary of results.

\begin{tabular}{|c|c|c|c|c|c|}
\hline Sample & Level & $E_{1}$ & $\operatorname{tg} \delta_{\max }$ & $N_{1} / N_{0}$ & $E_{\mathrm{PB}} / E_{\mathrm{B}}$ \\
\hline $\mathrm{A}$ & $\mathrm{T} 3$ & 0.34 & 7 & 0.22 & 0.91 \\
\hline $\mathrm{B}$ & $\mathrm{T} 3$ & 0.34 & 12 & 0.38 & $\begin{array}{c}\text { shoulder } \\
0.79\end{array}$ \\
\hline $\mathrm{T} 1$ & 0.20 & 17 & 0.70 & 0.91 \\
\hline $\mathrm{C}$ & $\mathrm{T} 3$ & 0.34 & 3 & 0.095 & 0.14 \\
\hline $\mathrm{T} 2$ & 0.28 & 4 & 0.81 \\
& $\mathrm{~T} 3$ & 0.34 & 15 & 0.46 & 0.90 \\
& & & & 0.72 \\
\hline
\end{tabular}

about $90 \%$ of the breakdown field $E_{\mathrm{B}} ; \mathrm{T} 2$ corresponds to a maximum at $81 \%$ and $\mathrm{T} 1$ to a maximum at $79 \%$. The maximum of $\alpha$ at $72 \%$ for sample D is perhaps related to the shoulder described earlier.

The absence of secondary maxima in medium voltage varistors is perhaps due to a lower amount of deep levels compared with that of low voltage varistors: the smaller grain size allows stronger doping of the material leading to a higher conductivity of the grains without degrading the leakage current.

Considering the existing models of electrical barriers, an increase of $\alpha$ is possible only with an abrupt decrease of barrier height $\phi_{\mathrm{B}}$. In the theoretical model of Blatter and Greuter [8] which includes one deep level of energy $E_{1}$, the variation of varrier height with voltage is given by :

$$
\phi_{\mathrm{B}}(V)=\frac{V_{\mathrm{B}}}{4}\left(1-\frac{V}{V_{\mathrm{B}}}\right)^{2}+\frac{N_{1}}{N_{0}+N_{1}} \frac{E_{1}}{q}
$$

with :

$$
V_{\mathbf{B}}=\frac{Q_{\mathrm{i}}^{2}(V)}{2 \varepsilon_{0} \varepsilon\left(N_{0}+N_{1}\right)} .
$$

If $Q_{\mathrm{i}}$ is independent on the applied voltage, the first term of equation (22) is a parabola. The second term of $\phi_{\mathrm{B}}$ cancels abruptly at a voltage $V_{\mathrm{PB}}$ when $\phi_{\mathrm{B}}$ has decreased of $\Delta \phi_{\mathrm{B}}=E_{1}$ (Fig. 8). This decrease is related to the slope of the parabola $\phi_{\mathrm{B}}(V)$, proportional to $V_{\mathrm{B}}$. If $V_{\mathrm{B}}$ does not depend on temperature, $V_{\mathrm{PB}}$ will not be thermally activated, that is what we did actually observe.

Another interpretation would involve the phenomenon of impact ionisation of the deep levels on the reverse biased side of the junction. In the same manner as the valence states are ionised by hot electrons near the breakdown voltage $V_{\mathrm{B}}[8]$ with an electroluminescence effect [9], the deep levels can be ionised by electrons with an energy lower to the gap $(3.2 \mathrm{eV})$. Recently, electroluminescence has

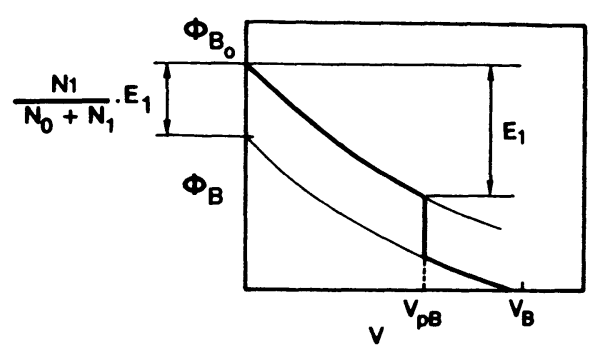

Fig. 8. - Theoretical variation of the barrier height with voltage in the prebreakdown region. The deep level at an energy $E_{1}$ below the conduction band is the cause of the abrupt jump of the curve at a voltage $V_{\mathrm{PB}}$ where a local maximum of $\alpha$ appears. 
been observed well below $V_{\mathrm{B}}$ and interpreted as being due to recombination of electrons and holes inside the gap on the deep levels [10].

\section{Conclusion.}

The characteristics of a varistor in the prebreakdown region can be described by the variation of the non linear coefficient $\alpha$ versus voltage or current. Some maxima of $\alpha$ are related to the presence of deep levels that can be analysed by admittance spectroscopy. These levels are the cause of abrupt jumps in the decreasing $\phi_{\mathrm{B}}(V)$ curve at fields below the breakdown field $E_{\mathrm{B}}$ of the barrier. The deeper level (at $0.34 \mathrm{eV}$ below the conduction band) causes a prebreakdown at $0.9 E_{\mathrm{B}}$ and the shallower one (at $0.20 \mathrm{eV}$ ) at about $0.8 E_{\mathrm{B}}$. The value of the non linearity coefficient at these voltages can be very high (up to 25).

\section{Appendix.}

Estimation of the error on the non linear coefficient evaluation.

The method of determination of $\alpha$ is an interpolation between the two voltages $V_{1}$ and $V_{2}=V_{1}+\delta V$. The corresponding current values are $I_{1}$ and $I_{2}=I_{1}+\delta I$. $\alpha$ is given by :

$$
\alpha=\frac{\operatorname{Ln} I_{2}-\operatorname{Ln} I_{1}}{\operatorname{Ln} V_{2}-\operatorname{Ln} V_{1}} .
$$

The relative error on $\alpha$ :

$$
\frac{\Delta \alpha}{\alpha}=\frac{2 \Delta(\operatorname{Ln} I)}{\operatorname{Ln}\left(I_{2} / I_{1}\right)}+\frac{2 \Delta(\operatorname{Ln} V)}{\operatorname{Ln}\left(V_{2} / V_{1}\right)} .
$$

Assuming $\delta V \ll V_{1}$, we can make a first order development of $\operatorname{Ln}\left(V_{2} / V_{1}\right)$ and we get :

$$
\frac{\Delta \alpha}{\alpha}=\frac{2 \Delta I}{I_{1} \operatorname{Ln}\left(I_{2} / I_{1}\right)}+\frac{2 \Delta V}{\delta V} .
$$

As $I_{2}=I_{1}+\delta I$ with $\delta I / I=\alpha \delta V / V$ :

$$
\frac{\Delta \alpha}{\alpha}=\frac{2}{\operatorname{Ln}(1+\alpha \cdot \delta V / V)} \frac{\Delta I}{I}+\frac{2 \Delta V}{\delta V} .
$$

The error on voltage evaluation is less than 10 $\mathrm{mV}$ : the second term is then less than $2 \%$. The relative error on current measurement is less than $5 \%$, the relative error on $\alpha$ due to the first term is then less than:

$$
\frac{\Delta \alpha}{\alpha}=\frac{0.1}{\operatorname{Ln}\left(1+\alpha \frac{\delta V}{V}\right)} .
$$

For $V=20$ volts and $\alpha=15$, the relative error is of $18 \%$.

\section{References}

[1] Mahan G. D., Levinson L. M., Philipp H. R., $J$. Appl. Phys. 50 (1979) 2799-2817.

[2] Hower P. L., Gupta T. K., J. Appl. Phys. 50 (1979) 4847-4855.

[3] Pike G. E., Phys. Rev. B 30 (1983) 795-802.

[4] Bernasconi J., Strassler S., Knecht B., Klein H. P., Menth A., Solid State Commun. 21 (1977) 867-870.

[5] Vincent G., Bois D., Pinard P., J. Appl. Phys. 46 (1975) 5173-5178.

[6] Cordaro J. F., Shim Y., May J. E., J. Appl. Phys. 60 (1986) 4186-4190.
[7] Gaucher P., Perrier R. L., Ganne J. P., 2nd Int. Conf. on varistors, Schenectady (December 1988).

[8] Blatter G., Greuter F., Phys. Rev. B 33 (1985) 3952-3966.

[9] Pike G. E., Kurtz S. R., Gourley P. L., PhilipP H. R., LeVinson L. M., J. Appl. Phys. 57 (1985) 5512-5519.

[10] Mirales A., Cornet A., Morante J. R., Semicond. Sci. Technol. 1 (1986) 230-233. 